Document downloaded from:

http://hdl.handle.net/10251/148015

This paper must be cited as:

Ressler, A.; Ródenas Rochina, J.; Ivankovic, M.; Ivankovic, H.; Rogina, A.; Ferrer, G. (2018). Injectable chitosan-hydroxyapatite hydrogels promote the osteogenic differentiation of mesenchymal stem cells. Carbohydrate Polymers. 197:469-477. https://doi.org/10.1016/j.carbpol.2018.06.029

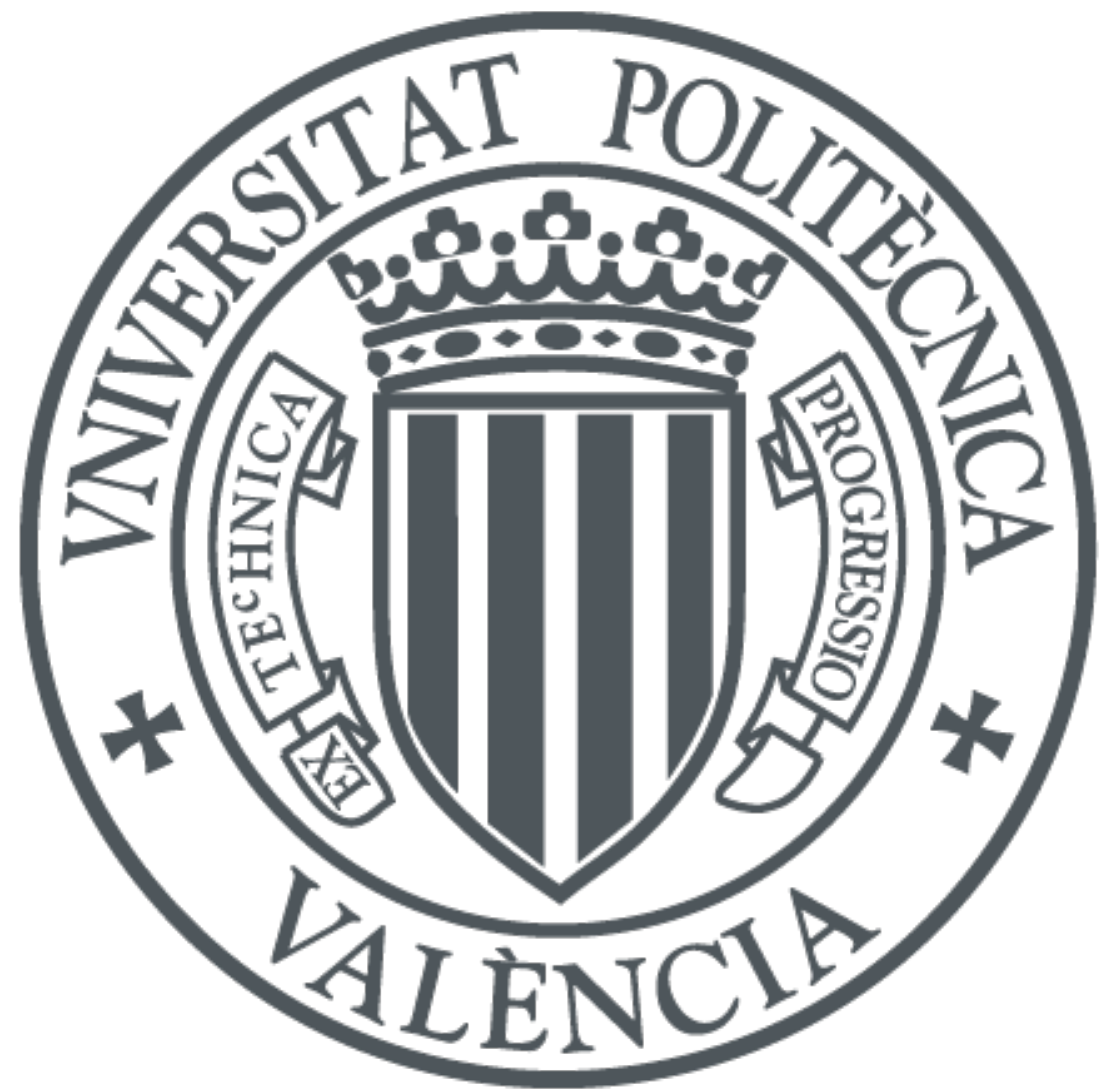

The final publication is available at

https://doi.org/10.1016/j.carbpol.2018.06.029

Copyright Elsevier

Additional Information 

26

\section{Injectable chitosan-hydroxyapatite hydrogels promote the osteogenic differentiation of mesenchymal stem cells}

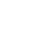

(1)

(1)

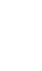

$$
\begin{gathered}
\text { Antonia Ressler }{ }^{\mathrm{a} ; *}, \text { Joaquín Ródenas-Rochina }{ }^{\mathrm{b}} \text {, Marica Ivanković }{ }^{\mathrm{a}}, \text { Hrvoje Ivanković }{ }^{\mathrm{a}} \text {, Anamarija } \\
\text { Rogina }^{\mathrm{a}} \text {, Gloria Gallego Ferrer }{ }^{\mathrm{b}, \mathrm{c}}
\end{gathered}
$$

${ }^{a}$ Faculty of Chemical Engineering and Technology, University of Zagreb, HR-10001 Zagreb, Marulićev trg 19, p.p.177, Croatia

${ }^{\mathrm{b}}$ Centre for Biomaterials and Tissue Engineering, Universitat Politècnica de València, Camino de Vera s/n, 46022 Valencia, Spain

c Biomedical Research Networking Centre in Bioengineering, Biomaterials and Nanomedicine (CIBER-BBN), Valencia, Spain

*Corresponding author: Antonia Ressler, Faculty of Chemical Engineering and Technology, University of Zagreb, HR-10001 Zagreb, Marulićev trg 19, p.p.177, Croatia, Tel: +385 014597210 , e-mail: $\underline{\text { aressler@fkit.hr }}$

E-mail addresses: aressler@fkit.hr (A. Ressler), jrodenasr@gmail.com (J. Ródenas Rochina), $\underline{\text { mivank@fkit.hr }}$ (M. Ivanković), hivan@fkit.hr (H. Ivanković), $\underline{\operatorname{arogina} @ f k i t . h r}$ (A. Rogina), ggallego@ter.upv.es (G. Gallego Ferrer).

5

.




\section{Abstract}

Injectable hydrogels have emerged as promising biomaterials for tissue engineering applications. The goal of this study was to evaluate the potential of a $\mathrm{pH}$-responsive chitosanhydroxyapatite hydrogel to be used as a three-dimensional support for encapsulated mesenchymal stem cells (MSCs) osteogenic differentiation. In vitro enzymatic degradation of the hydrogel, during 28 days of incubation, in simulated physiological condiditons, was characterized by swelling measurements, molecular weight determination and SEM analysis of hydrogel microstructure. Osteogenic differentiation of encapsulated MSCs was confirmed by osteogenic Runx2, collagen type I and osteocalcin immunostaining and alkaline phosphatase quantification. The deposition of late osteogenic markers (calcium phosphates) detected by Alizarin red and von Kossa staining indicated an extracellular matrix mineralization.

.

.

.

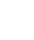

.

Keywords: chitosan; differentiation; hydrogel; hydroxyapatite; MSCs; osteogenesis

\section{8}




\section{Introduction}

Over the past decade, injectable hydrogels have emerged as promising biomaterials for tissue engineering applications since they are generally biocompatible, biodegradable and can mimic the extracellular matrix (ECM) architecture. With the fast development of cell-based therapies, there is a growing need to develop injectable hydrogels as cell carriers, potentially avoiding an open surgery procedure and facilitating the use of minimally invasive approaches for material and cell delivery. The hydrogel precursor loaded with cells can be injected into the wound site, and experiences a sol-gel transition in situ due to physical or chemical stimuli.

In the past years, many chitosan (Cht) based hydrogels have been developed for biomedical applications, as it is well documented and analyzed in review papers (Liu et al., 2017; Racine, Texier \& Auzély-Velty, 2017; Ta, Dass \& Dunstan, 2008). A particular focus has been on chitosan hydrogels based on thermosensitive sol-gel transition initiated by glycerophosphate salt at body temperature, invented by Chenite et al. (Chenite, Buschmann, Wang, Chaput, \& Kandani, 2001). The ability of chitosan-based hydrogels to support chondrogenic differentiation of human mesenchymal stem cells (hMSCs) has been confirmed (Cho et al., 2004; Dang et al., 2006). By combining chitosan-glycerophosphate with different concentrations of starch, a thermoresponsive hydrogel, that can be used as an injectable vehicle for cell delivery, has been prepared (Sa-Lima, Caridade, Mano, \& Reis, 2010). Naderi-Meshkin et al. (Naderi-Meshkin et al., 2014) have developed a chitosan based injectable hydrogel via the combination of chitosan, glycerol phosphate, and hydroxyethyl cellulose. Systematic investigations of the viability, proliferation, and differentiation capacity of encapsulated mesenchymal stem cells in the hydrogel have indicated that the hydrogel has a high potential for cartilage tissue engineering. The study with human adipose-derived stem cells grown on chitosan hydrogel, cross-linked by $0.5 \%$ glutaraldehyde, (Debnath et al., 2015) 
has revealed that chitosan hydrogel promotes cell proliferation coupled with $>90 \%$ cell viability.

Chitosan hydrogels loaded with inorganic particles, such as hydroxyapatite (HAp), which is the inorganic component of bone and constitutes $60 \%$ of native bone ECM, have been prepared to improve mechanical properties and bioactivity of hydrogels. The addition of hydroxyapatite phase into chitosan-based material has indicated better cell and protein adhesion, enhanced cell proliferation and higher osteogenic gene expression (Frohbergh et al., 2012; Peter et al., 2010). Moreover, stem cell culture on chitosan-hydroxyapatite scaffolds modified by growth factors has been proposed as good strategy for bone tissue reconstruction (Liu et al., 2013). In a recent study (Demirtas, Irmak \& Gümüşderelioğlu, 2017) a chitosan solution and its composite with nanostructured hydroxyapatite were mixed with cells and bioprinted successfully. It was observed that MC3T3-E1 pre-osteoblast cells within chitosan and chitosan-HA hydrogels had mineralized and differentiated osteogenically after 21 days of culture. It was proven that the presence of hydroxyapatite in chitosan hydrogels improved cell viability, proliferation and osteogenic differentiation.

In our recent study (Rogina et al., 2017b) a novel pH-responsive chitosanhydroxyapatite hydrogel, physically crosslinked with sodium bicarbonate, that allowed noncytotoxic fast gelation within 4 min, was prepared, with 30\% (w/w) of HAp phase. The in situ synthesis of apatite phase has facilitated the physical crosslinking by reducing the acidity of the chitosan solution. Preliminary biological characterization of the hydrogel, performed by MTT test and live-dead assay, indicated good distribution and viability of encapsulated mouse embryonic fibroblasts and good resistance to shear. Based on these results we hypothesized that proposed injectable hydrogel could be a suitable osteoconductive cellular carrier. 
In this work, as a continuation of previous studies, in vitro enzymatic degradation of the hydrogel, during 28 days of incubation, in simulated physiological condiditons, has been analyzed. To evaluate the osteogenic potential of the hydrogel, an extensive biological characterization has been preformed as well, using porcine mesenchymal stem cells. Since our recent studies proved the osteogenic potential of highly porous composite Cht/HAp scaffold, with $30 \mathrm{wt} \%$ of in situ formed HAp, prepared by precipitation reaction and freeze-gelation method in static and dynamic cell culture conditions (Rogina et al., 2016; Rogina et al., 2017a) in this work, we used the Cht/HAp scaffold, as a control. We hypothesized that the cellular response to chemically identical biomaterials may depend on the way the cells were incorporated in biomaterial. Therefore, two methods were applied: (1) MSCs were encapsulated during chitosan-hydroxyapatite hydrogel formation and (2) cells were seeded onto prefabricated porous chitosan-hydroxyapatite scaffold, and the results of biological characterization were compared.

\section{Materials and methods}

\subsection{Materials}

Chitosan (Cht, $M_{\mathrm{w}}=100-300 \mathrm{~kg} / \mathrm{mol}$, deacetylation degree of $0.95-0.98$, Acros Organics; sterilised with $96 \%$ of ethanol), calcium carbonate $\left(\mathrm{CaCO}_{3}\right.$, calcite; TTT; sterilised by autoclave), urea phosphate $\left(\left(\mathrm{NH}_{2}\right)_{2} \mathrm{CO}-\mathrm{H}_{3} \mathrm{PO}_{4}\right)$; Aldrich Chemistry; sterilised using 0.22 $\mu \mathrm{m}$ filter), acetic acid (99.5\%, Sigma Aldrich; sterilised using $0.22 \mu \mathrm{m}$ filter), sodium bicarbonate $\left(\mathrm{NaHCO}_{3}, \mathrm{Gram}-\mathrm{Mol}\right.$; sterilised using $0.22 \mu \mathrm{m}$ filter $)$, sodium hydroxide $(\mathrm{NaOH}$, Gram-Mol) and ethanol (EtOH, 96\% Kefo) were all of analytical grade. Lysozyme (from hen egg white, $\geq 54000 \mathrm{U} / \mathrm{mg}$ protein) in the form of powder was purchased from Sigma-Aldrich. 
2.2. Synthesis of $\mathrm{pH}$-responsive $\mathrm{Cht} / \mathrm{HAp}$ hydrogel and scaffold

Based on our previous study (Rogina et al., 2015) chitosan-hydroxyapatite suspension was prepared by in situ wet precipitation method. Briefly, $1.2 \mathrm{wt} \%$ of chitosan (Cht) solution was prepared in $0.36 \mathrm{wt} \%$ acetic acid $(\mathrm{HAc})$. Then, calcite $\left(\mathrm{CaCO}_{3}\right)$ and urea phosphate $\left(\left(\mathrm{NH}_{2}\right)_{2} \mathrm{CO}-\mathrm{H}_{3} \mathrm{PO}_{4}\right)$ were added into Cht solution with $\mathrm{Ca} / \mathrm{P}$ ratio of 1.67 to obtain $30 \mathrm{wt} \%$ of hydroxyapatite in final composite. This HAp content was selected based on our previous studies on chitosan composite scaffolds (Rogina et al., 2015; Rogina et al., 2016; Rogina et al., 2017a) where it resulted optimal in terms of mechanical and biological response as stimulates osteogenesis.

The mixture was stirred 4 days at $50{ }^{\circ} \mathrm{C}$. After 4 days of reaction, the $\mathrm{Cht} / \mathrm{HAp}$ suspension was cooled down naturally to ambient temperature and used for preparation of $\mathrm{pH}$-responsive hydrogel (1) and control material (2).

(1) The $\mathrm{pH}$-responsive, Cht/HAp system was prepared using $0.067 \mathrm{mg} / \mathrm{L}$ solution of sodium bicarbonate prepared in basal $\alpha$-MEM (minimum essential medium), as described previously (Rogina et al., 2017b). After cooling down the Cht/HAp suspension and $\mathrm{NaHCO}_{3} / \alpha-\mathrm{MEM}$ solution to $10{ }^{\circ} \mathrm{C}$ using ice bath, components were mixed together for $10 \mathrm{sec}$ by stirring at $1700 \mathrm{rpm}$. Homogenized suspension was then incubated at $37{ }^{\circ} \mathrm{C}$ to initiate physical crosslinking of Cht/HAp hydrogel.

(2) The Cht/HAp scaffolds prepared by thermally induced phase separation and extraction (Rogina et al., 2015) were used as control materials. Briefly, Cht/HAp suspension was frozen over night at $-22{ }^{\circ} \mathrm{C}$ and immersed in $\mathrm{NaOH} / \mathrm{EtOH}(1: 1$ of volume portion) solution for $12 \mathrm{~h}$ at $-22{ }^{\circ} \mathrm{C}$. Then, samples were immersed in ethanol for $12 \mathrm{~h}$ at $-22{ }^{\circ} \mathrm{C}$ and finally dehydrated in ethanol for $24 \mathrm{~h}$, at ambient temperature.

\subsection{In vitro enzymatic degradation}



different concentrations of lysozyme $(1.5 \mu \mathrm{g} / \mathrm{mL}$ corresponding to an activity of $82 \mathrm{U} / \mathrm{mL}$ and $500 \mu \mathrm{g} / \mathrm{mL}$ corresponding to an activity of $27300 \mathrm{U} / \mathrm{mL}$ ) under static physiological

151

152

165 Dry weight remaining ratio $(\%)=\frac{W_{d}}{W_{d 0}} \times 100$

Swelling ratio $(\%)=\frac{W_{s}-W_{d}}{W_{d}} \times 100$ conditions (phosphate buffer saline solution, PBS) on five replicas. Crosslinked hydrogels ( $n$ $=5,500 \mu \mathrm{L}$ ) were incubated in $5 \mathrm{~mL}$ of PBS containing lysozyme at $37^{\circ} \mathrm{C}$ during 28 days.

Freshly prepared degradation medium was changed every third day to maintain the activity of lysozyme and to mimic physiological conditions in vivo (Porstmann et al., 1989). The Cht/HAp hydrogels were also incubated in phosphate buffer saline solution without containing lysozyme. At defined time points, the degradation medium was carefully removed in order to determine the weight of swollen hydrogel samples $\left(W_{\mathrm{s}}\right)$. Then, samples were lyophilised $\left(W_{\mathrm{d}}\right)$ and swelling ratio was calculated according to equation 1 :

The degradation of hydrogels was determined as the ratio of remaining hydrogel weight $\left(W_{\mathrm{d}}\right)$ and initial weight of the sample ( $\left.W_{\mathrm{d} 0}\right)$ before enzymatic degradation (Eq. 2$)$.

The influence of degradation medium on hydrogels' microstructure was analysed by scanning electron microscopy (SEM). Dried degraded samples were coated with plasma of gold and palladium for $90 \mathrm{~s}$. The microscopic imaging was carried out by the electron microscope TESCAN Vega3SEM Easyprobe at electron beam energy of $15 \mathrm{keV}$. 
2.4. Gel permeation chromatography

The distribution of molecular weight of Cht/HAp hydrogels during enzymatic degradation was analysed by Gel Permeation Chromatography (GPC), at $35^{\circ} \mathrm{C}$, with a Waters Breeze GPC system and a 1525 Binary HPLC pump (Waters Corporation, Milford, MA) equipped with a 2414 refractive index detector and four serial columns of water (Ultrahydrogel $7.8 \mathrm{~mm}$ ID X $30 \mathrm{~cm}$ ). The degraded hydrogel samples were dissolved in acetic buffer $\left(\mathrm{CH}_{3} \mathrm{COOH} 0.5 \mathrm{M} / \mathrm{CH}_{3} \mathrm{COONa} 0.2 \mathrm{M}, \mathrm{pH}=4.5\right)$ used as a mobile phase at a flow rate of $0.5 \mathrm{~mL} / \mathrm{min}$ and $20 \mu \mathrm{L}$ injection volume, as previously described by Gámiz-González et al. (Gámiz-González et al., 2015).

\subsection{Cell encapsulation/seeding}

Porcine mesenchymal stem cells from bone marrow were obtained, using a modified protocol for human MSCs isolation (Gamiz-Gonzalez et al., 2017; Lennon \& Caplan, 2006; RodenasRochina, Kelly, Ribelles \& Lebourg, 2016; Thorpe et al., 2008). For expansion, the cells were seeded at $4 \times 10^{5}$ cells $/ \mathrm{cm}^{2}$ in a T75 $\mathrm{cm}^{2}$ culture flask with high glucose Dulbecco's modified Eagle's medium (DMEM), enriched with 10\% of FBS, 2\% penicillin/streptomycin and 125 $\mu \mathrm{g} / \mathrm{mL}$ amphotericin B until passage 1 . From passage 1 to 3 culture media was supplemented with $5 \mathrm{ng} / \mathrm{mL}$ recombinant human fibroblast growth factor- 2 and without amphotericin B. Cells at passage 3 were used for tri-potentiality assessment (Thorpe et al., 2008) and cell culture seeding.

For cell encapsulation, the cells were resuspended at a density of $1.4 \times 10^{6}$ cells $/ \mathrm{mL}$ in a $\mathrm{Cht} / \mathrm{HAp} / \mathrm{NaHCO}_{3}$ solution, with $\mathrm{pH}$ of 7.01 and at $10{ }^{\circ} \mathrm{C}$ suitable for cell survival, as described in our previous study (Rogina, et al.; 2017b). 
195 The cell/hydrogel system was quickly seeded on 24-well plates, $200 \mu \mathrm{L}$ per well, and 196 incubated in humidified atmosphere at $37{ }^{\circ} \mathrm{C}$ and $5 \%$ of $\mathrm{CO}_{2}$ for 4 min to induce physical 197 crosslinking. Then, samples were incubated with $2 \mathrm{~mL}$ of DMEM medium supplemented with $10 \%$ of FBS (fetal bovine serum) and $1 \%$ of penicillin/streptomycin in a humidified atmosphere with $5 \% \mathrm{CO}_{2}$ at $37{ }^{\circ} \mathrm{C}$ for $24 \mathrm{~h}$. After $24 \mathrm{~h}$, basal medium was changed with DMEM supplemented with $10 \%$ of FBS, $1 \%$ of penicillin/streptomycin, $50 \mu \mathrm{g} / \mathrm{mL}$ of ascorbic acid, $10 \mathrm{mmol} / \mathrm{L}$ of $\beta$-glycerophosphate and $1 \mu \mathrm{mol} / \mathrm{L}$ of dexamethasone. The medium was refreshed every third day.

As a control material, Cht/HAp scaffolds were cut into cylindrical shape pieces of $7 \mathrm{~mm}$ diameter and 1-2 mm height, sterilized in $96 \%$ ethanol and conserved at $4{ }^{\circ} \mathrm{C}$ for $24 \mathrm{~h}$. After sterilization, scaffolds were washed 3 times with Dulbecco's modified Eagle's culture medium (DMEM), left in DMEM for $24 \mathrm{~h}$ and transported into 24-well plate. Scaffolds were seeded with the same cell density as hydrogels, according to the volume of the scaffold. The cells suspension was put on top of the scaffold and incubated for 15 min to allow cells attachment and migration inside the scaffold. Then cell culture media was added in the same way as for the hydrogels.

\subsection{Cell Counting}

Cell proliferation into Cht/HAp hydrogels and control materials was examined at 1, 7 and 14 days of culture. After cutting three $50 \mu \mathrm{m}$ slices, of five different replicas, samples were stained with DAPI. Images were taken by confocal fluorescence microscope (Zeiss LSM 780, Axio Observer) in 16-tile mode scanning and the cell nuclei were counted. Average number of cells at different time points is expressed as average value corrected by standard error of the mean (SEM). 
2.7. Alkaline phosphatase analysis

The activity of alkaline phosphatase (ALP) was measured as the conversion of $\mathrm{p}$ nitrophenylphosphate to p-nitrophenol as the result of the cellular extract activity, using SensoLyte ${ }^{\circledR}$ pNPP Alkaline Phosphatase Assay kit *Colorimetric* (AnaSpec) according to the manufacturer instructions. Samples were gathered at 7 and 14 days. For each time point, three acellular samples were used as blanks. After washing the samples with Dulbecco's phosphate buffered saline (DPBS) and lysis buffer (DPBS 1X with $0.2 \%$ Triton X-100) solution, $200 \mu \mathrm{L}$ of lysis buffer was added and homogenized with hydrogel. All samples were incubated in ice bath and centrifuged at $4{ }^{\circ} \mathrm{C}$ for $7 \mathrm{~min}$ to precipitate cellular and material debris. Then, $50 \mu \mathrm{L}$ of each standard and sample with $50 \mu \mathrm{L}$ of p-nitrophenylphosphate were placed in 96-well plate in triplicates. The plate was incubated in the dark for $40 \mathrm{~min}$ at room temperature. Absorbance was measured at $405 \mathrm{~nm}$ using Perkin-Elmer VICTOR3 multi-plate reader. The concentration of the ALP was determined using a standard curve.

\subsection{Immunofluorescent imaging of cell markers}

Differentiation of MSCs at 7 and 14 days was evaluated by different antibodies to confirm the expression of differentiation markers: runt-related transcription factor 2 (Runx2), collagen type I (COLL I) and osteocalcin (OCN). Cultured samples were fixed in $4 \%$ of formaldehyde at $4{ }^{\circ} \mathrm{C}$ for $1 \mathrm{~h}$ and washed with DPBS. Sample slices of Cht/HAp hydrogels with $50 \mu \mathrm{m}$ of thickness were permeabilized with DPBS/0.5\% Triton X-100 for $5 \mathrm{~min}$ at room temperature, further treated with $1 \%$ of sodium dodecyl sulfate (SDS) in DPBS for 5 minutes to perform the antigen retrieval, and subsequently washed with DPBS. Then, samples were blocked by DPBS/1\% bovine serum albumin (BSA)/10\% goat serum for 30 min. Incubation 
DPBS/ $1 \%$ bovine serum BSA /10\% goat serum, was performed for $5 \mathrm{~h}$ at room temperature.

Further, samples were washed with DPBS/0.05\% Tween 20 surfactant and incubated with

Bodipy FL Dye (Fisher) dilution 1:400 to stain the cytoskeleton and secondary antibody antimouse conjugated with alexa 555 for $1 \mathrm{~h}$ at room temperature. Incubation with secondary antibodies was not performed for Runx2, because primary antibody is labelled FITC. Finally, samples were mounted with Vectashield DAPI for nuclei staining. Detection of protein markers was performed by confocal fluorescence microscope (Zeiss LSM 780, Axio Observer).

The staining antibodies on control materials were performed on whole sample. After washing second antibodies, control materials were fixed and included in cryoprotective medium at -80 ${ }^{\circ} \mathrm{C}$. Then, samples were cut into slices with $50 \mu \mathrm{m}$ of thickness and mounted with Vectashield DAPI.

\subsection{Histological Analysis}

Cultured samples were fixed with formaldehyde, included in optimum cutting temperature compound (OCT), frozen at $-80{ }^{\circ} \mathrm{C}$ and cut into slices with $17 \mu \mathrm{m}$ of thickness. Detection of phosphate deposits on Cht/HAp hydrogels were determined using von Kossa staining. Samples were washed with distilled water and incubated in a $5 \% \mathrm{AgNO}_{3}$ solution (Sigma-Aldrich) under ultraviolet light for $20 \mathrm{~min}$. Further, samples were washed with distilled water and $2 \% \mathrm{Na}_{2} \mathrm{~S}_{2} \mathrm{O}_{3}$ (Sigma-Aldrich) to remove unreacted $\mathrm{AgNO}_{3}$. Finally, the cells were stained using a neutral red solution (Sigma-Aldrich) for 2 minutes. Detection of calcium deposits was determined using Alizarin red S staining. Samples were incubated with $2 \%$ of alizarin red solution ( $\mathrm{pH}$ of 4.2; Sigma-Aldrich) for 4 minutes. After staining, samples were washed with distilled water and mounted with $80 \%$ of glycerol solution (SigmaAldrich). 
2.10. Statistical analysis

All experiments were performed in triplicates or more. Statistical comparison between two groups was tested using one-way ANOVA test with value $p<0.05$ and $p<0.01$ considered statistically significant.

\section{Results}

\subsection{In vitro degradation testing}

In the present study, enzymatic degradation of Cht/HAp hydrogel was studied at $37{ }^{\circ} \mathrm{C}$ as a function of time, for 28 days, by monitoring swelling behaviour, dry weight loss, molecular weight $\left(M_{w}\right)$ and polydispersity index $(P D I)$. To distinguish between enzymatic degradation and dissolution, Cht/HAp hydrogels were exposed to phosphate buffer solution (PBS) without and with (1.5 and $500 \mu \mathrm{g} / \mathrm{mL})$ lysozyme, as used in reported studies (Jin et al., 2009; Moura, Faneca, Lima, Gil \& Figueiredo, 2011; Yang et al., 2010). The lysozyme concentration of $500 \mu \mathrm{g} / \mathrm{mL}$ better mimics the in vivo physiological conditions, as the lysozyme level in the extracellular matrix of human tissues can increase up to 1,000-fold (Hou et al., 2012) the amount usually found in serum $(0.95 \sim 2.45 \mu \mathrm{g} / \mathrm{mL}$ ) (Jin et al., 2009; Park, Choi \& Lee, 2013;).

The results shown in Fig. 1a suggest an increase in swelling ratio with incubation time for all investigated systems. However, there is no significant difference in swelling ratios among 3 , 14 and 28 days for Cht/HAp hydrogels (Fig. 1a) incubated in non-enzymatic conditions (Cht/HAp_PBS) and in $1.5 \mu \mathrm{g} / \mathrm{mL}$ of lysozyme solution (Cht/HAp_1.5 $\mu \mathrm{g} / \mathrm{mL})$. For Cht/HAp hydrogel incubated in the $500 \mu \mathrm{g} / \mathrm{mL}$ of lysozyme solution (Cht/HAp_500 $\mu \mathrm{g} / \mathrm{mL}$ ) there is a significant difference between swelling ratios between 3 and 28 days. As seen from Figure $1 \mathrm{~b}$ the weight loss of Cht/HAp hydrogel in different incubation media follows the decreasing 
trend: PBS $<1.5 \mu \mathrm{g} / \mathrm{mL}$ of lysozyme solution $<500 \mu \mathrm{g} / \mathrm{mL}$ of lysozyme solution. However, there is no significant difference in dry weight remaining ratio among 3, 14 and 28 days. Weight average molecular weight $\left(M_{w)}\right.$ reduction during incubation was observed in all investigated systems (Fig. 1c), and the degradation is the most pronounced in $500 \mu \mathrm{g} / \mathrm{mL}$ of lysozyme solution. Initial molecular weight, $M_{w 0} \approx 222000$, decreased after 3 and 28 days, in non-enzymatic condition to 170000 and 113000 , respectively, in $1.5 \mu \mathrm{g} / \mathrm{mL}$ of lysozyme solution to 123000 and 79000 , respectively, and in $500 \mu \mathrm{g} / \mathrm{mL}$ of lysozyme solution to 48 000 and 36 500, respectively. Polydispersity index stayed around 2 throughout all degradation process which could indicate a random depolymerisation (Holme, Davidsen, Kristiansen \& Smidsrød, 2008).

In all investigated systems the decrease in molecular weight is accompanied by an increase of the swelling ratio, but only in system Cht/HAp_500 $\mu \mathrm{g} / \mathrm{mL}$ a significant difference in swelling ratio between 3 and 28 days was observed. It is expected that shorter chitosan chains in Cht/HAp_500 $\mu \mathrm{g} / \mathrm{mL}$, show smaller extent of chain entanglements and physical crosslinking density, compared to other two investigated systems, resulting in higher swelling ratios. To provide a better understanding of the correlation between chitosan molecular weight and swelling ratio other molecular parameters that describe the network structure of hydrogels should be determined, such as the critical entanglement molecular weight and the average molecular weight between crosslinks. (i.e., mesh size). 

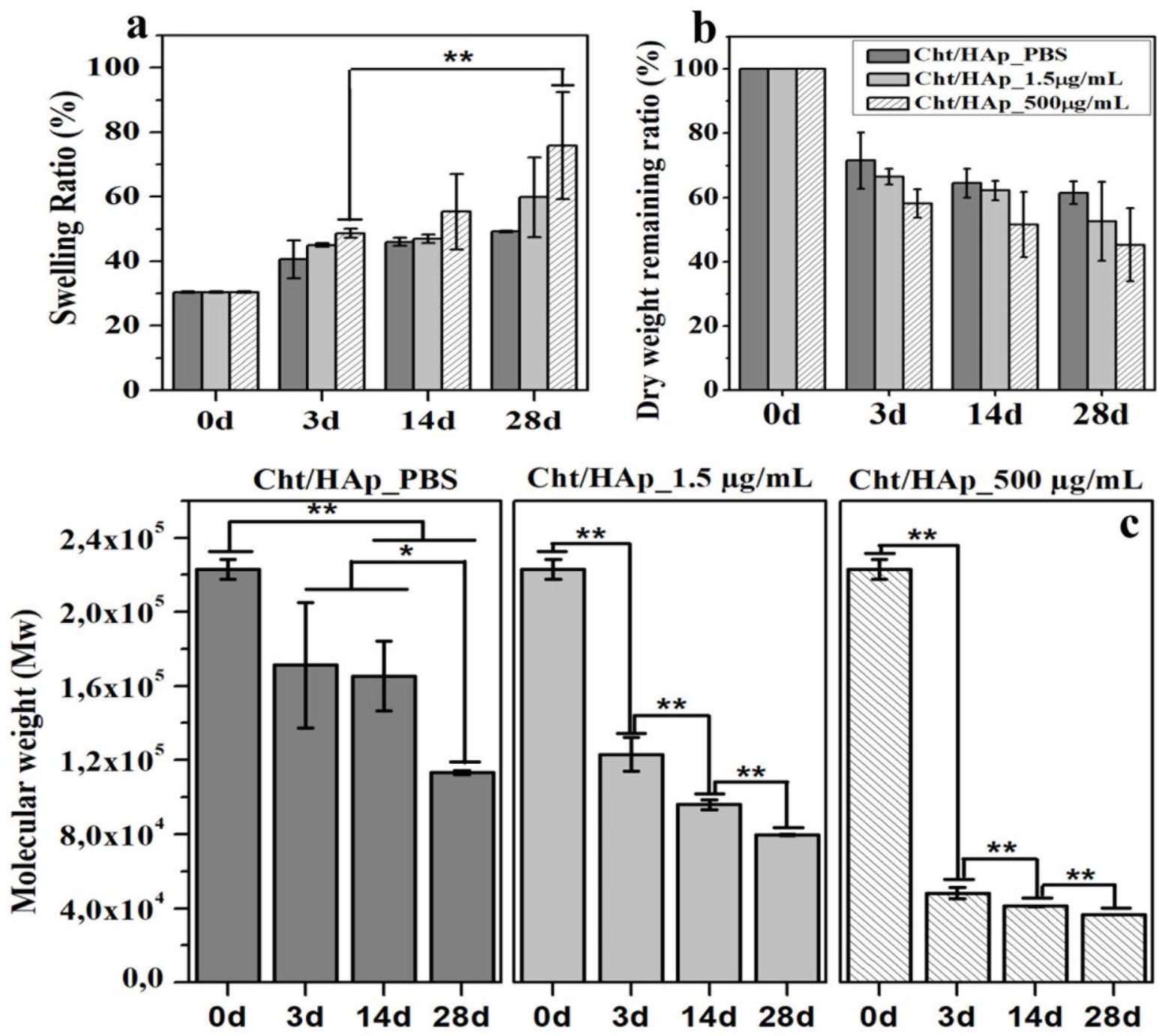

311 Fig. 1. Swelling ratio (a); dry weight remaining ratio (b); and weight average molecular weight (c) of Cht/HAp hydrogel incubated in different degradation media at $37{ }^{\circ} \mathrm{C}$ as a function of time. Significant difference between two groups: $*(p<0.05), * *(p<0.01)$.

The microstructures of the cross section of Cht/HAp_PBS and Cht/HAp_1.5 $\mu \mathrm{g} / \mathrm{mL}$ hydrogels shown in Fig. $2 \mathrm{~b}$ confirm larger pores after 3 days of incubation at $37^{\circ} \mathrm{C}$ compared to initial Cht/HAp hydrogel (0 day), as a result of water absorption. The pore structure of Cht/HAp_500 $\mu \mathrm{g} / \mathrm{mL}$ hydrogel is fully disrupted after 3 days of incubation as a result of high degradation rate. However, it retained the porous structure which is important for the diffusion of nutrients, metabolic waste products, and oxygen. In this study, deacetylation degree of chitosan is in the range $0.95-0.98$ and a high stability under enzymatic conditions 
322 porous structure was maintained in all degradation conditions indicating a stable Cht/HAp

323 hydrogel. SEM micrographs of Cht/HAp hydrogels cross section confirmed uniform

324 degradation through entire volume of hydrogel and good particles distribution of in situ

325 precipitated HAp within chitosan matrix (see Fig. 2a). In comparison to the hydrogel prepared

326 by mixing previously prepared hydroxyapatite particles within chitosan/ $\beta$-glycerophosphate

327 (Chen et al., 2016) in situ precipitation performed in this work results in smaller particles size.
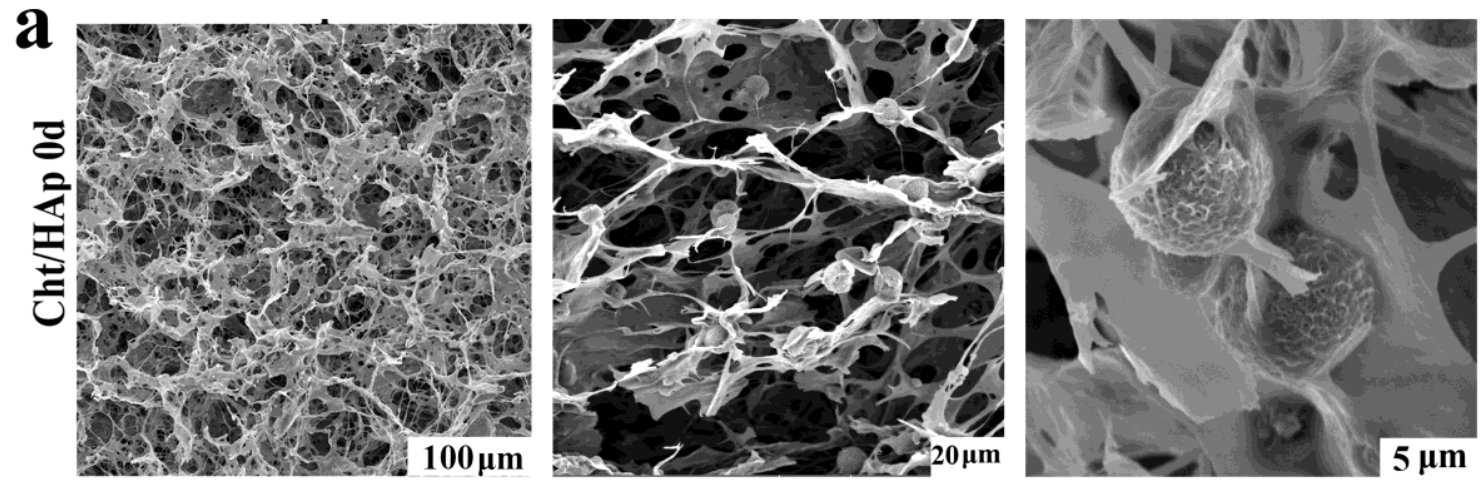

b

Cht/HAp_1.5 $\mu \mathrm{g} / \mathrm{mL}$

Cht $/$ HAp_500 $\mu \mathrm{g} / \mathrm{mL}$
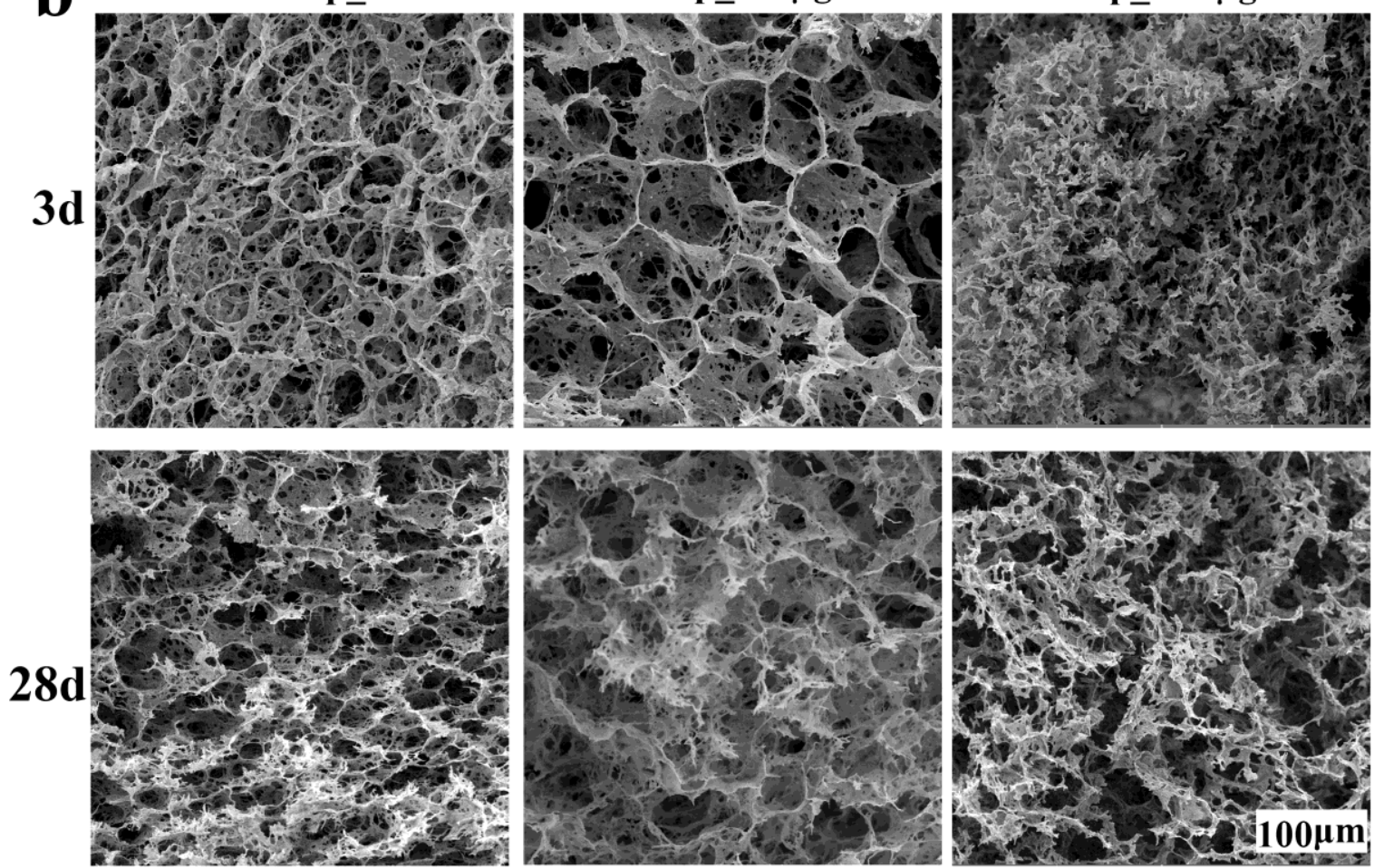
Fig. 2. SEM micrographs of dried hydrogel with in situ precipitated HAp particles within chitosan matrix (a) and Cht/HAp hydrogel incubated for 3 and 28 days under different degradation conditions (b).

\subsection{Biological characterization}

As described in experimental section, for both, the hydrogel and the scaffold, the cell counting was performed by imaging three DAPI stained $50 \mu \mathrm{m}$ slices, of five different replicas. Images were taken by confocal fluorescence microscope in 16-tile mode scanning. Fig $3 a$ represents the average cell number of the total 16 tiles at 3 different slices. It is noteworthy that counted cell number does not represent total cell number, but average number of cells on material slices imaged in 16-tile mode.

As shown in Fig. 3a, lower cell number on scaffold at day 0, compared to hydrogel was observed, although, the same number of cells were encapsulated in the hydrogel and seeded on the scaffold. It could indicate that all cells did not succeed to achieve a stable adhesion and could easily detach from the scaffold. An increase in the number of cells after 7 days of culture was obtained in both $\mathrm{Cht} / \mathrm{HAp}$ hydrogel and the control, indicating that new injectable Cht/HAp hydrogel is suitable for cell encapsulation and proliferation and can be used as a cell carrier for bone tissue engineering. After an initial increase in cell number, there is not a significant difference in the average cell number between 7 and 14 days. This could indicate that cells stopped proliferating and probably started to differentiate, what was confirmed by the presence of osteogenic markers, as will be shown below. Figure S1 of Supplementary material confirms that cells stayed homogeneously dispersed inside hydrogel during 14 days of cell culture indicating that the microstructure and physically crosslinked chitosan chains do not allow cell to migrate outside the hydrogel. 

there is no significant difference in ALP concentration (Fig. 3b) between 7 and 14 days of cell culture in the Cht/HAp hydrogel, it seems that the tendency is to increase with the culture time. A clear significant increase of ALP secretion was measured in the control scaffolds.
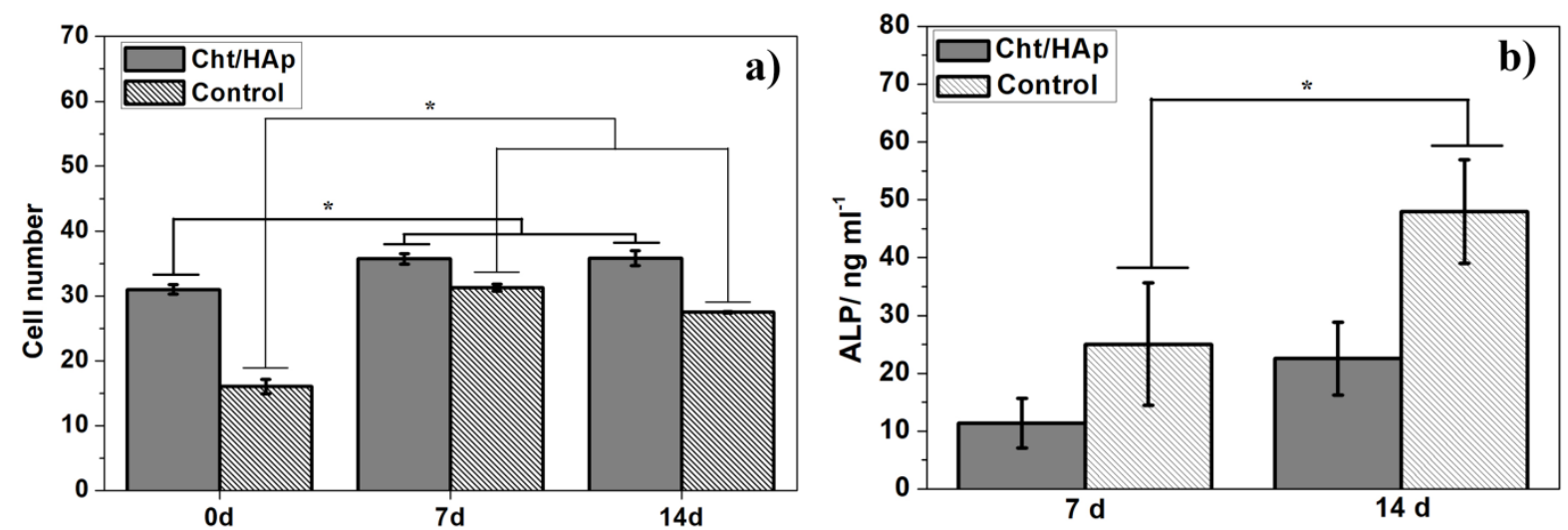

Fig. 3. The cell number (a) and alkaline phosphatase activity (ALP) (b) of MSCs encapsulated in Cht/HAp hydrogel and control after 7 and 14 days of cell culture. Significant difference between two groups $(p<0.05)$ is designated with $(*)$.

Along with ALP activity quantification, osteogenic differentiation of MSC cells encapsulated in Cht/HAp hydrogel was determined by analysing the expression of runt-related transcription factor 2 (Runx2), collagen I (COLL I) and osteocalcin (OCN) at 7 and 14 days of cell culture. Images obtained by confocal fluorescence microscopy are shown in Fig. 4a-c. Cell nuclei stained with DAPI appeared in blue, while Runx2 (Fig. 4a) appeared in green, COLL I (Fig. 4b) and OCN (Fig. 4c) appeared in red and cytoskeleton (actin) in green. Unfortunately, the quality of immunofluorescence images is poor due to strong autofluorescence of hydrogel/scaffold. To minimize the sample interference the images were processed by ImageJ software, which resulted in darkening of the final image. To compensate

371 this we completed the study with additional colorimetric stains (alizarin red and von Kossa) as will be shown later. 
373 Previous in vitro studies (Komori, 2003) demonstrated that Runx2 can enhance the expression

374 of bone matrix genes like collagen type I, osteopontin, osteocalcin, bone sialoprotein (BSP)

375 and fibronectin. According to that, expression of COLL I and OCN was expected and found at

3767 and 14 days of cell culture, implying good osteogenic potential of prepared Cht/HAp

377 hydrogel. The round shape morphology of MSCs is evident after 7 and 14 days of cell culture,

378 which is consistent with the literature (Wang, Rao \& Stegemann, 2013; Caliari, Vega, Kwon,

379 Soulas \& Burdick, 2016). 


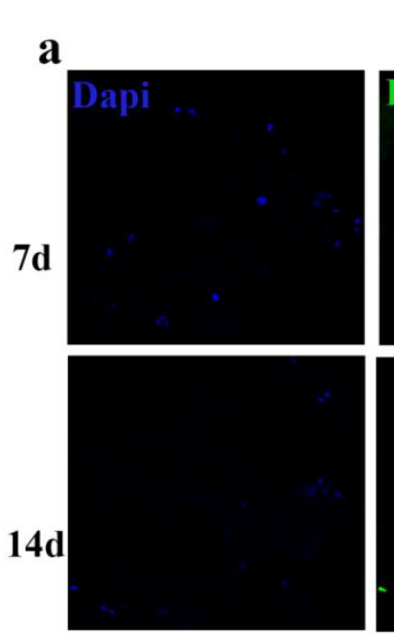

b
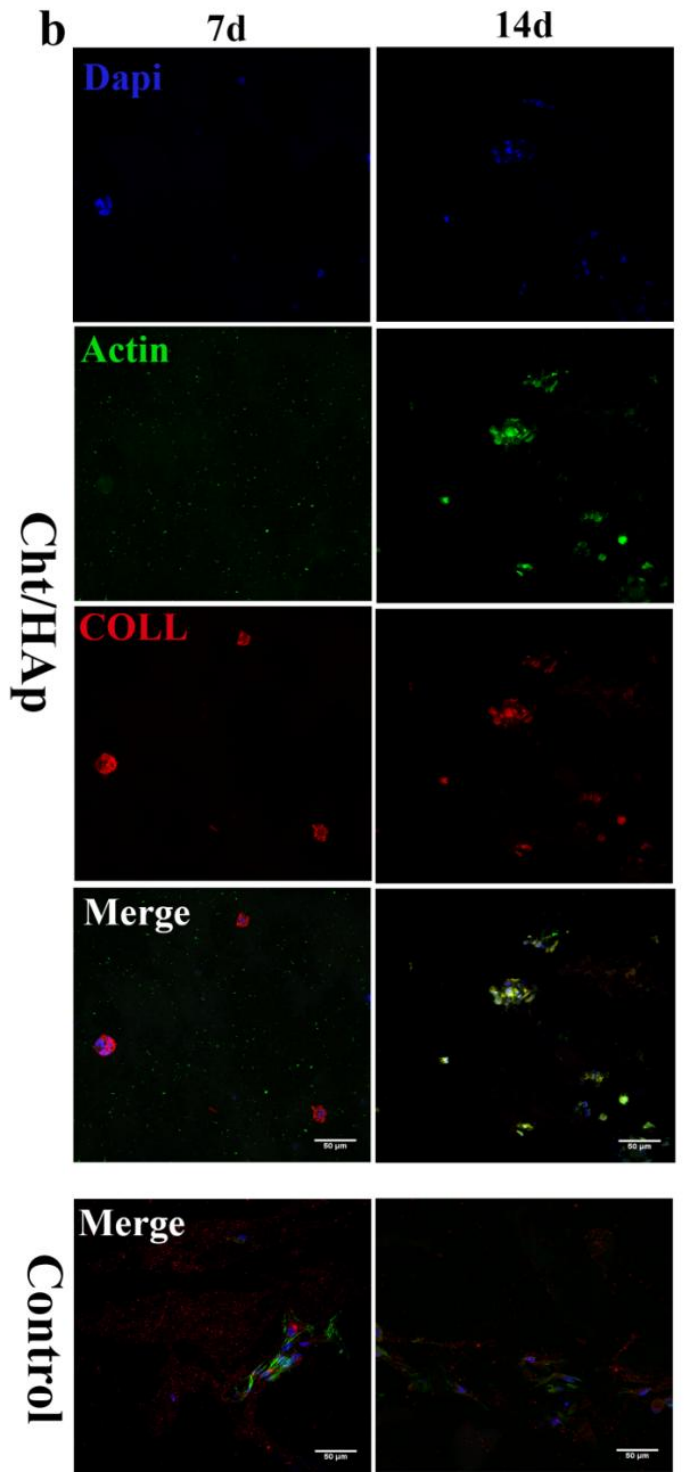

Cht/HAp
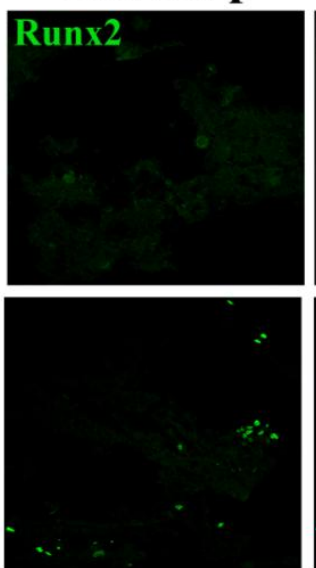

$14 d$

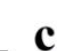

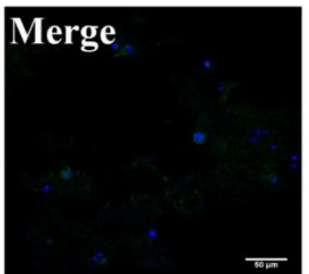

\section{Control}
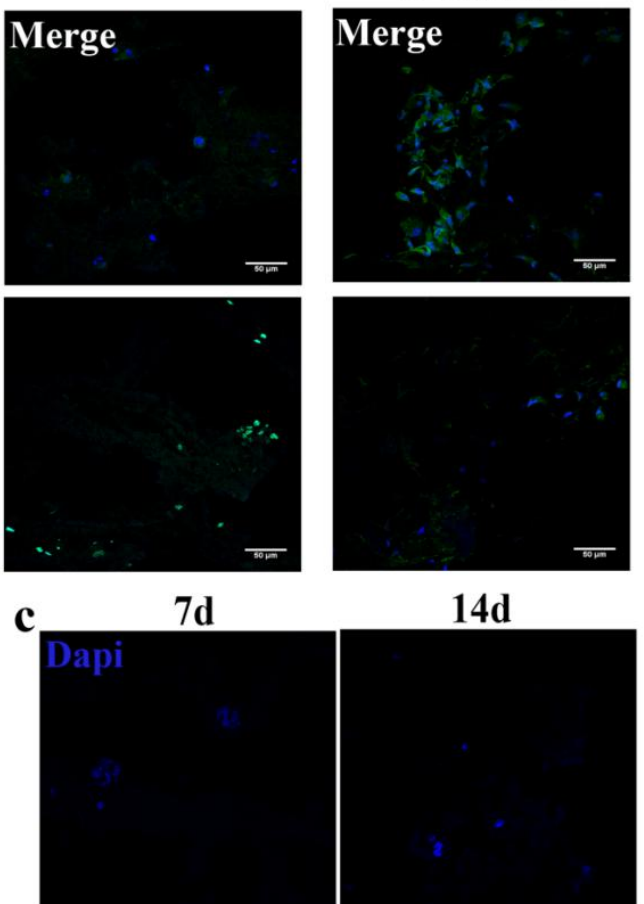

14d
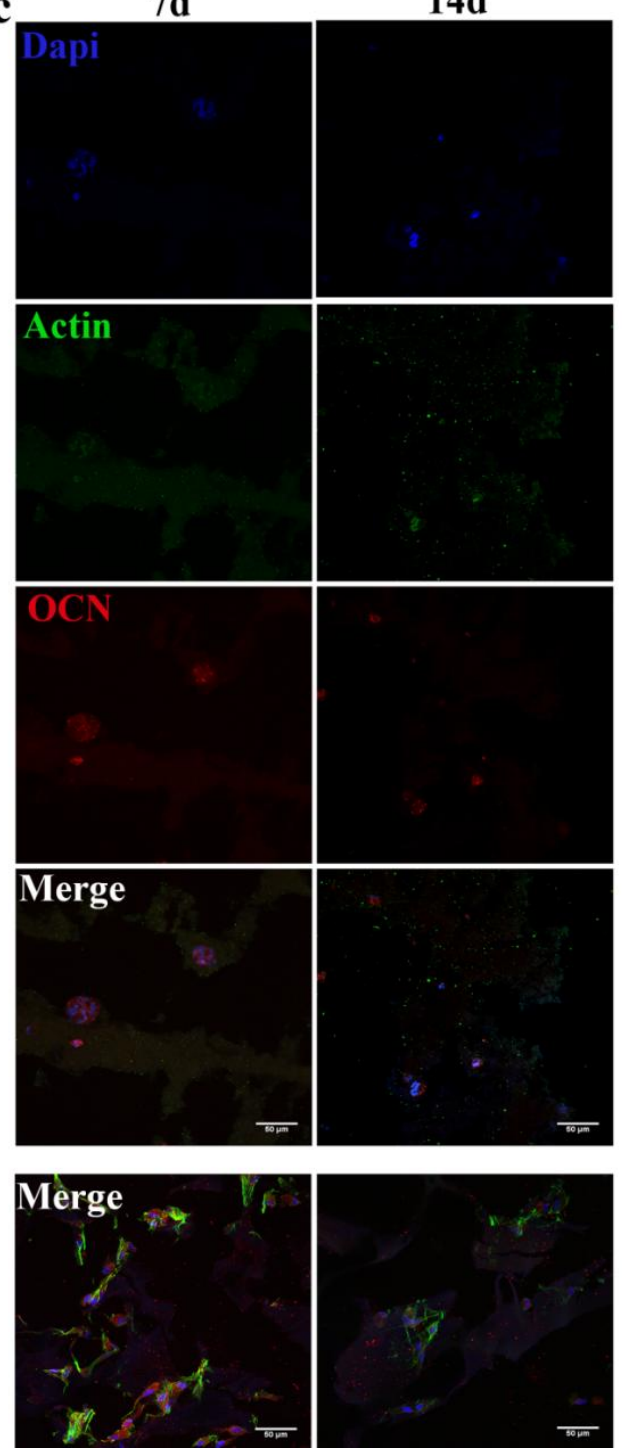

381 Fig. 4. The expression of Runx2 (a), collagen type I (COLL I) (b) and osteocalcin (OCN) (c) 382 encapsulated in Cht/HAp hydrogels after 7 and 14 days of cell culture. Cell nucleus stained 383 with Dapi (blue fluorescence), Runx2 (green fluorescence) (a). Actin cytoskeleton stained 
with phallacidin (green fluorescence), COLL I and OCN (red fluorescence) (b and c). Scale bar: $50 \mu \mathrm{m}$.

Mineralized ECM in the Cht/HAp hydrogels was identified by von Kossa and Alizarin red staining (Fig. 5), where calcium deposits are positively stained in red and phosphate deposits in brown or black. After 7 and 14 days of culture higher intensity of red and brown (black) deposits indicate that mineralization of ECM occurred. Obtained results of differentiated cells after 7 and 14 days of cell culture were compared with $\mathrm{Cht} / \mathrm{HAp}$ hydrogel with undifferentiated cells at day 0 (Ctrl in Fig. 5).

Alizarin red

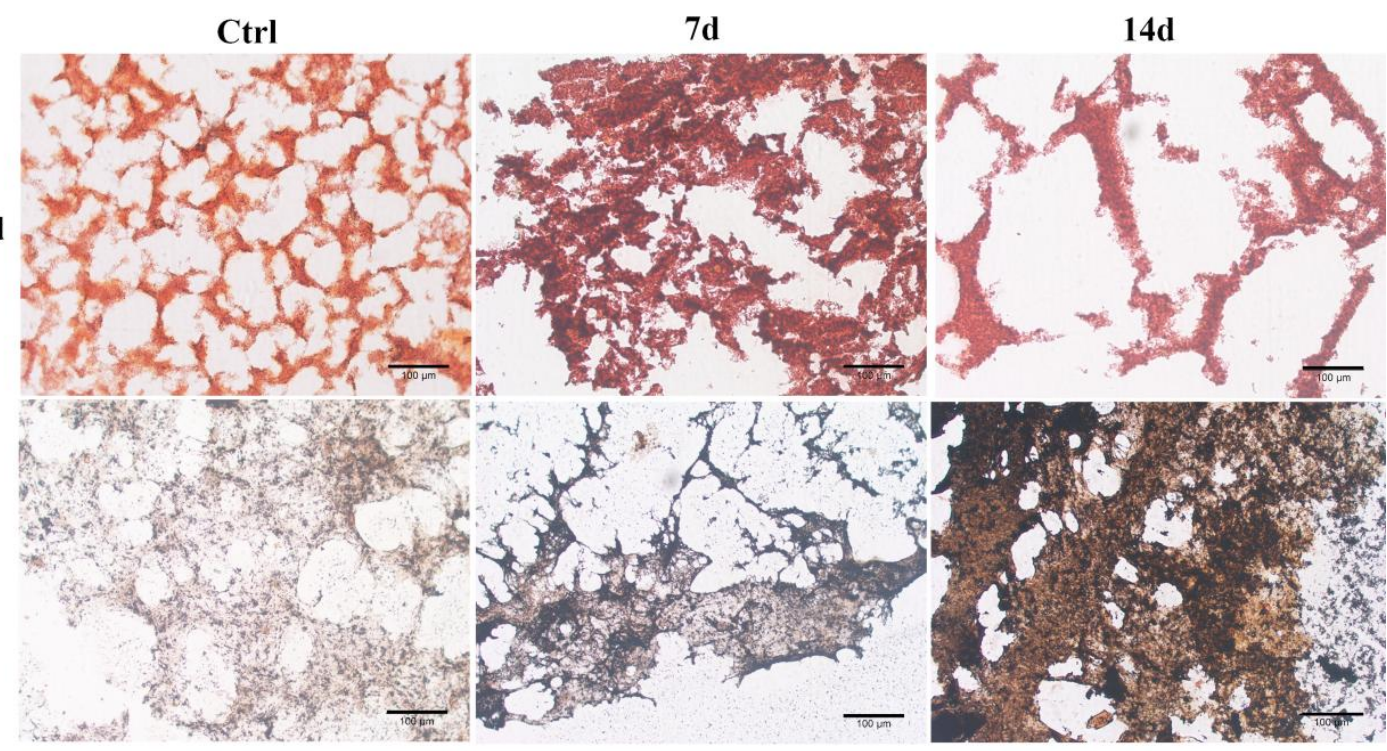

Fig. 5. Positive staining for calcium deposits after 7 and 14 days of culture is observable by red colour determined using alizarin red $\mathrm{S}$ assay. Positive staining for phosphate deposits after 7 and 14 days is observable by brown and black colour determined using von Kossa assay. Cht/HAp hydrogel with undifferentiated cells was used to indicate the material/cell interference (Ctrl). Scale bar: $100 \mu \mathrm{m}$.

\section{Discussion}


In our previous study (Rogina et al., 2017b) an injectable, pH-responsible, physically

crosslinked hydrogel based on chitosan and in situ formed hydroxyapatite, with $30 \%(\mathrm{w} / \mathrm{w})$ of HAp phase, was prepared. The viscoelastic behaviour of hydrogel was observed in the range of strain deformation up to approximately $10 \%$. The $\mathrm{G}^{\prime \prime} / \mathrm{G}^{\prime}$ ratio of 0.04 and linear viscoelasticity above $5 \%$ of strain deformation, indicated that chitosan/HAp hydrogel could behave as a strong physical gel. Compared to the storage modulus of similar physically crosslinked chitosan-based system, with $30 \%(\mathrm{w} / \mathrm{w})$ of bioglass nanoparticles, and $\beta$ glycerophosphate as a gelling agent (Couto, Hong \& Mano, 2009) our gel showed 1.5-fold higher storage modulus, indicating better resistance to shear. Distribution and viability of encapsulated mouse embryonic fibroblasts within the hydrogel up to 7 days of culture was confirmed by live dead staining.

As a continuation of previous study, in this work an extensive in vitro characterization of the hydrogel, using porcine MSCs, was performed, including, in vitro enzymatic degradation during 28 days of incubation, in simulated physiological condiditons. It was hypothesized that in situ synthesis of hydroxyapatite within chitosan matrix would provide a homogeneous dispersion of hydroxyapatite particles with positive influence on osteoinduction and differentiation of MSCs that can lead to homogeneous bone regeneration.

Swelling behaviour, structural integrity and rate of degradation are critical variables in hydrogel design that affect the rate of tissue formation. Hydrogels derived from natural polymers often are not stable at physiological conditions and undergo rapid degradation (Tan \& Marra, 2010). As cell carriers, hydrogels stability during cell encapsulation and differentiation at physiological conditions is required. Chitosan has the ability to readily swell up when exposed in a biological environment. Degradation of chitosan takes place via hydrolysis, as interactions with water molecules break the polymeric network into smaller chains whereby the $\beta-1-4 \mathrm{~N}$-acetyl glucosamine units of Cht undergo chain scission mainly by 
lysozymes present in the body. This phenomenon leads to release of amino sugars, which can be incorporated into metabolic pathways or excreted through the body (Liu, Zhou \& Sun, 2012; Qasim et al., 2017; Ren, Yi, Wang \& Ma, 2005; Tomihata \& Ikada, 1997). Other by products of Cht degradation include saccharides which become part of the normal metabolic process (Kumar, Muzzarelli, Muzzarelli, Sashiwa \& Domb, 2004).

The results obtained in this work show that new physically crosslinked Cht/HAp hydrogel is highly stable during 28 days, even in extreme conditions with much higher concentration of lysozyme than physiological, which is important for the eventual future clinical application of the material. The weight loss after 28 days of incubation is comparable to the literature data reported for chemically crosslinked hydrogels based on chitosan, showing $30-70 \%$ weight loss after 28 days of incubation under enzymatic physiological conditions, depending on crosslinking degree (Moura et al., 2011; Xu et al., 2016). The big advantage of the synthesis applied in present work is simple chitosan gel formation, feasible under mild conditions, without using toxic cross-linking agents. The cross-sectional SEM images of the freeze-dried hydrogels (Fig. 2) demonstrate a porous and netlike structure and good particles distribution of in situ precipitated HAp within chitosan matrix. The porous structures provide an environment suitable for the attachment, growth, and differentiation of MSCs, and transport of nutrients to the cells.

Many in vitro and in vivo studies have suggested that MSCs have the potential to enhance osteogenesis while being delivered in critical sized bone defects with ability to migrate to defect sites. Despite MSCs capacity to differentiate to osteoblasts, MSCs ability to support a regenerative microenvironment is of great importance. MSCs can differentiate to multiple cell types like chondrocytes, osteoblasts and adipocytes (Oryan, Kamali, Moshiri \& Baghaban Eslaminejad, 2017). MSCs were encapsulated in an injectable thermosensitive chitosanglycerophosphate where differentiation occurred to chondrocytes (Richardson, Hughes, Hunt, 
449 Freemont \& Hoyland, 2008). The same tendency was observed in other chitosan based

450

451

452

453

454

455

456

457

458

459

460

461

462

463

464

465

466

467

468

469

470

471

472 hydrogels (Cho et al., 2004; Jin, 2009; Hu, 2012). Wang and Stegemann (Wang \& Stegemann, 2010) used $\beta$-glycerophosphate as gelling agent to obtain physically crosslinked chitosan hydrogel. High concentration of $\beta$-glycerophosphate was required to obtain gelation time below $10 \mathrm{~min}$. Additionally, DNA content of encapsulated human bone marrow mesenchymal stem cells decreased over time suggesting that cells were dying in chitosan hydrogel. Incorporation of previously prepared HAp particles into chitosan/gelatin scaffold enhanced osteogenic differentiation (Zhao, Grayson, Ma, Bunnell \& Lu, 2006). In the present work the differentiation of MSCs encapsulated in the Cht/HAp hydrogel was evaluated after 7 and 14 days of cell culture. Colorimetric quantification of alkaline phosphatase activity and immunofluorescent imaging was used to detect the expression of osteogenic markers.

Detection of Runx2 as a principal osteogenic master gene for bone formation as well as COLL I and OCN, characteristic genes of differentiation process, indicates good osteogenic signal of Cht/HAp hydrogel where MSCs differentiated into an osteoblast phenotype indicating possible application of Cht/HAp hydrogel as cell carrier for bone tissue engineering.

Osteogenesis depends on the material's composition, surface properties, charge and wettability, but also on the material stiffness. Literature reports that stiffness of about $1,5 \mathrm{kPa}$ upregulated osteogenic expression whereas softer matrices are not so osteogenic (Murphy, Matsiko, Haugh, Gleeson \& O'Brien, 2012). That is the possible reason why the injectable Cht/HAp hydrogel that possess a lower modulus, around $100 \mathrm{~Pa}$ (Rogina et.al. 2017b) than the Cht/HAp scaffold has a lower ALP activity compared to the scaffold.

The deposition of late osteogenic markers (calcium phosphates) detected by Alizarin red and Von Kossa staining indicated an extracellular matrix (ECM) mineralization. It can be 
concluded that $\mathrm{Cht} / \mathrm{HAp}$ hydrogel provide suitable environment for enhanced osteogenesis of MSCs. Further in vivo studies on animal model need to be performed to examine biodegradation and osteogenesis to confirm the applicability of Cht/HAp hydrogel for bone tissue engineering.

\section{Conclusion}

Present research has shown that novel chitosan/hydroxyapatite physically crosslinked hydrogel act as the three-dimensional support for MSCs proliferation and differentiation into osteoblast cells. The expression of characteristic bone genes, Runx2, ALP, COLL I, OCN and calcium phosphate deposits, indicated that ECM mineralisation took place during 14 days of cell culture. MSCs are homogeneously dispersed through entire Cht/HAp hydrogel during cell culture, which is crucial for full bone healing. Prepared Cht/HAp hydrogel is highly stable under physiological and enzymatic conditions supporting the osteogenesis of encapsulated mesenchymal stem cells.

\section{Acknowledgements}

This work has been supported in part by the Croatian Science Foundation under the project IP-2014-09-3752 by the Spanish Ministry through the MAT2016-76039-C4-1-R project (including the FEDER financial support). The authors want to thank Laura Teruel Biosca from Centre for Biomaterials and Tissue Engineering, Universitat Politècnica de València, for helping with gel permeation chromatography measurements. Joaquin RódenasRochina acknowledges funding by the Consellería de Educación, Investigación, Cultura y Deporte (Generalitat Valenciana) and co-funding by Fondo Social Europeo (FSE) through APOSTD grant (APOSTD/2016/006).

\section{References}


Caliari, S. R., Vega, S. L., Kwon, M., Soulas, E. M., \& Burdick, J. A. (2016). Dimensionality and spreading influence MSC YAP/TAZ signaling in hydrogel environments. Biomaterials, $103,314-323$.

Chen, Y., Zhang, F., Fu, Q., Liu, Y., Wang, Z., \& Qi, N. (2016). In vitro proliferation and osteogenic differentiation of human dental pulp stem cells in injectable thermo-sensitive chitosan/b-glycerophosphate/hydroxyapatite hydrogel. Journal of Biomaterials Applications, $31,317-327$.

Chenite, A., Buschmann, M., Wang, D., Chaput, C., \& Kandani, N. (2001). Rheological characterisation of thermogelling chitosan/glycerol-phosphate solutions. Carbohydrate Polymers, 46, 39-47.

Cho, J. H., Kim, S. H., Park, K. D., Jung, M. C., Yang, W. I., Han, S. W., Noh, J. Y., \& Lee, J. W. (2004). Chondrogenic differentiation of human mesenchymal stem cells using a thermosensitive poly(N-isopropylacrylamide) and water-soluble chitosan copolymer. Biomaterials, 25, 5743-5751.

Couto, D. S., Hong, Z., \& Mano, J. F. (2009). Development of bioactive and biodegradable chitosan-based injectable systems containing bioactive glass nanoparticles. Acta Biomaterialia, 5, 115-123.

Dang, J. M., Sun, D. D., Shin-Ya, Y., Sieber, A. N., Kostuik, J. P., \& Leong, K. W. (2006). Temperature-responsive hydroxybutyl chitosan for the culture of mesenchymal stem cells and intervertebral disk cells. Biomaterials, 27, 406-418.

Debnath, T., Ghosh, S., Potlapuvu. U. S., Kona, L., Kamaraju, S. R., Sarkar, S., Gaddam, S., \& Chelluri, L. K. (2015). Proliferation and Differentiation Potential of Human Adipose- 

e0120803.

520

521

Demirtaş, T. T., Irmak, G., \& Gümüşderelioğlu, M. (2017). A bioprintable form of chitosan hydrogel for bone tissue engineering. Biofabrication, 9, Article number:035003.

Freier, T., Koh, H. S., Kazazian, K., \& Shoichet, M. S. (2005). Controlling cell adhesion and degradation of chitosan films by N-acetylation. Biomaterials, 26, 5872-5878.

Frohbergh, M. E., Katsman, A., Botta, G. P., Lazarovici, P., Schauer, C. L., Wegst, U. G. K., \& Lelkes, P. I. (2012). Electrospun hydroxyapatite-containing chitosan nanofibers crosslinked with genipin for bone tissue engineering. Biomaterials, 33, 9167-9178.

Gámiz-González, M. A., Guldris, P., Antolinos Turpín, C. M., Ródenas Rochina, J., Vidaurre, A., \& Gómez Ribelles, J. L. (2017). Fast degrading polymer networks based on carboxymethyl chitosan, Materials Today Communications, 10, 54-66.

Holme, H. K., Davidsen, L., Kristiansen, A., \& Smidsrød, O. (2008). Kinetics and mechanisms of depolymerization of alginate and chitosan in aqueous solution. Carbohydrate Polymers, 73, 656-664.

Hou, Y. P., Hu, J. L., Park, H., \& Lee, M. (2012). Chitosan-based nanoparticles as a sustained protein release carrier for tissue engineering applications. Journal of Biomedical Materials Research A, 100, 939-944.

Hu, J., Hou, Y., Park, H., Choi, B., Hou, S., Chung, A., \& Lee, M. (2012). Visible light crosslinkable chitosan hydrogels for tissue engineering. Acta Biomaterialia, 8, 1730-1738.

Jin, R., Moreira Teixeira, L. S., Dijkstra, P. J., Karperien, M., van Blitterswijk, C. A., Zhong, Z. Y., \& Feijen, J. (2009). Injectable chitosan-based hydrogels for cartilage tissue engineering. Biomaterials, 30, 2544-2551. 
541 Komori, T. (2003). Requisite roles of Runx2 and Cbfb in skeletal development. Journal of Bone and Mineral Metabolism, 21, 193-197.

543 Kumar, M. N. V. R., Muzzarelli, R. A. A., Muzzarelli, C., Sashiwa, H., \& Domb, A. J. 544 (2004). Chitosan chemistry and pharmaceutical perspectives. Chemical Reviews, 104, 60175456084.

546 Lennon, D. P., \& Caplan Al. (2006). Isolation of human marrow-derived mesenchymal stem 547 cells. Experimental Hematology, 34, 1604-1605.

548 Liu, H., Peng, H., Wu, Y., Zhang, C., Cai, Y., Xu, G., Li, Q., Chen, X., Ji, J., Zhang, Y., 549 OuYang, H. W. (2013). The promotion of bone regeneration by nanofibrous 550 hydroxyapatite/chitosan scaffolds by effects on integrin-BMP/Smad signaling pathway in 551 BMSCs. Biomaterials, 34, 4404-4417.

552 Liu, M., Zeng, X., Ma, C., Yi., H., Ali, Z., Mou, X., Li, S., Deng, Y., \& He, N. (2017). 553 Injectable hydrogels for cartilage and bone tissue engineering. Bone Research, 5, Article 554 Number: 17014.

555 Liu, Y., Zhou, C., \& Sun, Y. (2012). A biomimetic strategy for controllable degradation of 556 chitosan scaffolds. Journal of Materials Research, 27, 1859-1868.

557 Moura, M. J., Faneca, H., Lima, M .P., Gil, M. H., \& Figueiredo, M. M. (2011). In Situ 558 Forming Chitosan Hydrogels Prepared via Ionic/Covalent Co-Cross-Linking. 559 Biomacromolecules, 12, 3275-3284.

560 Murphy, C. M., Matsiko, A., Haugh, M. G., Gleeson, J. P., \& O’Brien, F. J. (2012).

561 Mesenchymal stem cell fate is regulated by the composition and mechanical properties of 562 collagen-glycosaminoglycan scaffolds. Journal of the Mechanical Behavior of Biomedical 563 Materials, 11, 53-62. 
564 Naderi-Meshkin, H., Andreas, K., Matin, M. M., Sittinger, M., Bidkhori, H. R., Ahmadiankia, 565 N., Bahrami, A. R., \& Ringe, J. (2014). Chitosan-based injectable hydrogel as a promising in 566 situ forming scaffold for cartilage tissue engineering. Cell Biology International, 38, $72-84$.

567 Oryan, A., Kamali, A., Moshiri, A., \& Baghaban Eslaminejad, M. (2017). Role of 568 Mesenchymal Stem Cells in Bone Regenerative Medicine: What Is the Evidence?. Cells 569 Tissues Organs, 204, 59-83.

570 Park, H., Choi, B., Hu, J., \& Lee, M. (2013). Injectable chitosan hyaluronic acid hydrogels for 571 cartilage tissue engineering. Acta Biomaterialia, 9, 4779-4786.

572 Peter, M., Ganesh, N., Selvamurugan, N., Nair, S. V., Furuike, T., Tamura, H., \& Jayakumar, 573 R. (2010). Preparation and characterization of chitosan-gelatin/nanohydroxyapatite composite 574 scaffolds for tissue engineering applications. Carbohydrate Polymers, 80, 687-694.

575 Porstmann, B., Jung, K., Schmechta, H., Evers, U., Pergande, M., Porstmann, T., Kramm, H. 576 J., \& Krause, H. (1989). Measurement of lysozyme in human body fluids: comparison of 577 various enzyme immunoassay techniques and their diagnostic application. Clinical 578 Biochemistry, 22, 349-355.

579 Qasim, S. B., Husain, S., Huang, Y., Pogorielov, M., Deineka, V., Lyndin, M, Rawlinson, A., 580 \& Rahman, I. U. (2017). In-vitro and in-vivo degradation studies of freeze gelated porous 581 chitosan composite scaffolds for tissue engineering applications. Polymer Degradation and $582 \quad$ Stability, 136, 31-38.

583 Racine L., Texier, I., \& Auzély-Velty, R. (2017). Chitosan-based hydrogels: recent design 584 concepts to tailor properties and functions. Polymer International, 66, 981-998. 
585

Ren, D., Yi, H., Wang, W., \& Ma, X. (2005). The enzymatic degradation and swelling properties of chitosan matrices with different degrees of $\mathrm{N}$-acetylation. Carbohydrate research, 340, 2403-2410.

Richardson, S. M., Hughes, N., Hunt, J. A., Freemont, A. J., \& Hoyland, J. A. (2008). Human mesenchymal stem cell differentiation to NP-like cells in chitosan-glycerophosphate hydrogels. Biomaterials, 29, 85-93.

Rodenas-Rochina, J., Kelly, D. J., Ribelles, J. L. G., \& Lebourg, M. (2016). Compositional changes to synthetic biodegradable scaffolds modulate the influence of hydrostatic pressure on chondrogenesis of mesenchymal stem cells. Biomedical Physics \& Engineering Express, 2, Article Number: 035005.

Rogina, A., Antunović, M., Pribolšan, L., Caput Mihalić, K., Vukasović, A., Ivković, A., Marijanović, I., Gallego Ferrer, G., Ivanković, M., \& Ivanković, H. (2017a). Human mesenchymal stem cells differentiation regulated by hydroxyapatite content within chitosanbased scaffolds under perfusion conditions. Polymers, 9, 387-404.

Rogina, A., Ressler, A., Matić, I., Gallego Ferrer, G., Marijanović, I., Ivanković, M., \& Ivanković H. (2017b). Cellular hydrogels based on pH-responsive chitosan-hydroxyapatite system. Carbohydrate Polymers, 166, 173-182.

Rogina, A., Rico, P., Gallego Ferrer, G., Ivanković, M. \& Ivanković, H. (2015). Effect of in situ formed hydroxyapatite on microstructure of freeze-gelled chitosan-based biocomposite scaffolds. European Polymer Journal, 68, 278-287.

Rogina, A., Rico, P., Gallego Ferrer, G., Ivanković, M., \& Ivanković, H. (2016). In situ hydroxyapatite content affects the cell differentiation on porous chitosan/hydroxyapatite scaffolds. Annals of Biomedical Engineering,. 44, 1107-1119. 
Sá-Lima H., Caridade, S. G., Mano, J. F., \& Reis, R. L. (2010). Stimuli-responsive chitosanstarch injectable hydrogels combined with encapsulated adipose-derived stromal cells for articular cartilage regeneration. Soft Matter, 6, 5184-5195.

Ta, H. T., Dass, C. R., \& Dunstan, D. E. (2008). Injectable chitosan hydrogels for localised cancer therapy. Journal of Controlled Release, 126, 205-216.

Tan, H., \& Marra, K. G. (2010). Injectable, biodegradable hydrogels for tissue engineering applications. Materials, 3, 1746-1767.

Thorpe, S. D., Buckley, C. T., Vinarfell, T., O’Brien, F. J., Campbell, V. A., \& Kelly, D. J. (2008). Dynamic compression can inhibit chondrogenesis of mesenchymal stem cells. Biochemical and Biophysical Research Communications, 377, 458-462.

Tomihata, K., \& Ikada,Y. (1997). In vitro and in vivo degradation of films of chitin and its deacetylated derivatives. Biomaterials, 18, 567-575.

Wang, L., Rao, R. R., \& Stegemann, J. P. (2013). Delivery of Mesenchymal Stem Cells in Chitosan/Collagen Microbeads for Orthopedic Tissue Repair. Cells Tissues Organs, 197, $333-343$.

Wang, L., \& Stegemann, J. P. (2010). Thermogelling chitosan and collagen composite hydrogels initiated with $\beta$-glycerophosphate for bone tissue engineering. Biomaterials, 31, $3976-3985$.

Xu, H., Zhang, L., Bao, Y., Yan, X., Yin, Y., Li, Y., Wang, X., Huang, Z., \& Xu, P. (2016). Preparation and characterization of injectable chitosan-hyaluronic acid hydrogels for nerve growth factor sustained release. Journal of Bioactive and Compatible Polymers, 32, 1-17. 
630 Preparation and characterization of a novel chitosan scaffold. Carbohydrate Polymers, 80, $631860-865$

632 Zhao, F., Grayson, W. L., Ma, T., Bunnell, B., \& Lu, W. W. (2006). Effects of hydroxyapatite

633 in 3-D chitosan-gelatin polymer network on human mesenchymal stem cell construct 634 development. Biomaterials, 27, 1859-1867.

635

636 Supplementary data

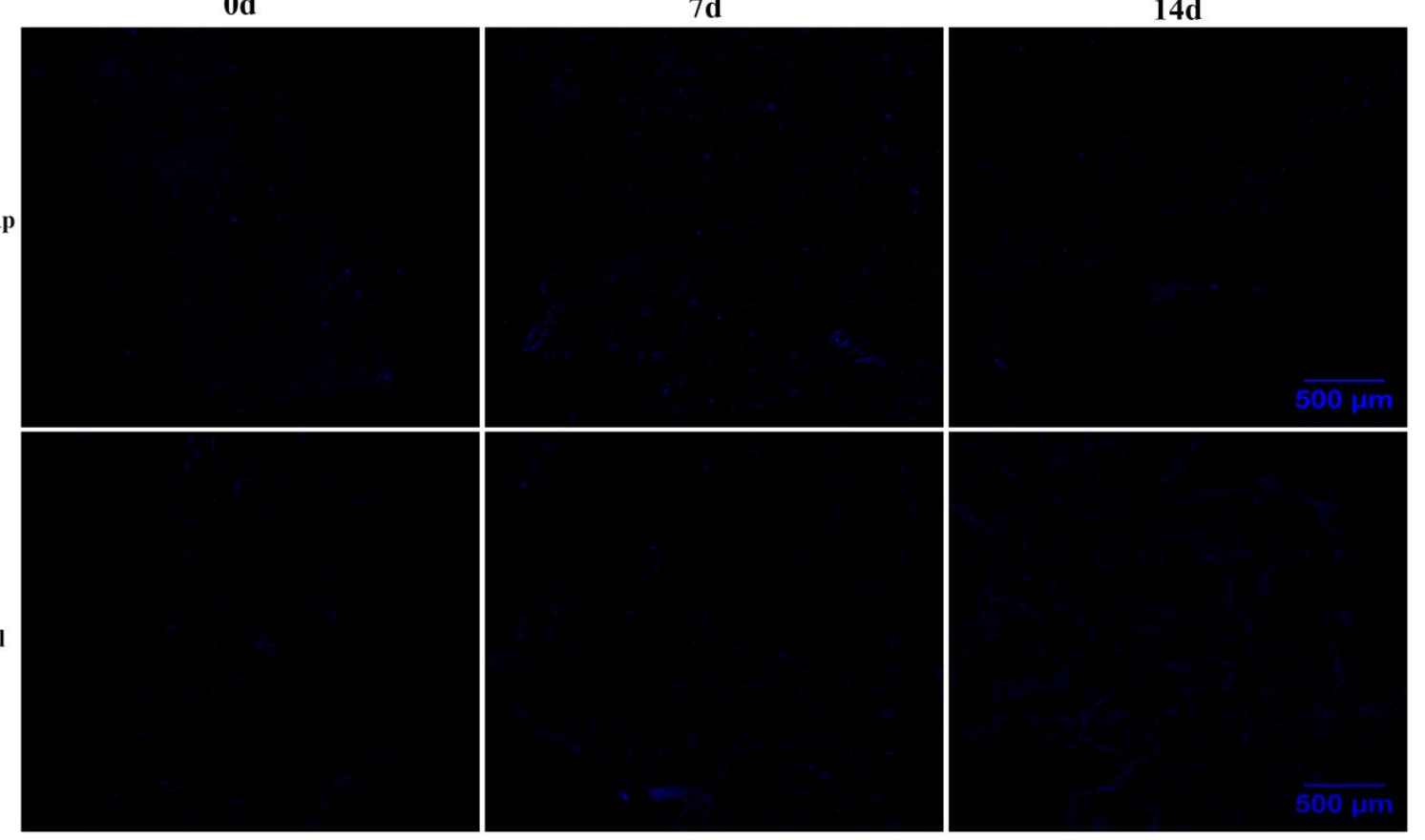

Cht/HAp

Control

638 Figure 1. Cell distribution through the cross section of Cht/HAp hydrogel and Control after 0, 
644

645

646

647

648

649 